\title{
Covariation for Microsatellite Marker Alleles Associated with Rht8 and Coleoptile Length in Winter Wheat
}

\author{
Guihua Bai,* Modan K. Das, Brett F. Carver, Xiangyang Xu, and Eugene G. Krenzer
}

\begin{abstract}
Wheat (Triticum aestivum L.) cultivars with greater coleoptile elongation are preferred in low-precipitation dryland regions and in early-planted management systems of the Great Plains, but the presence of GA3 (gibberellin)-insensitive dwarfing genes tends to restrict coleoptile elongation. The agronomic value of $R h t 8$ and the discovery of its diagnostic microsatellite marker, Xgwm 261, have accelerated breeders' interest in $R \boldsymbol{h t}$ t8 as an alternative dwarfing gene. Our objectives were to determine allelic distributions at the marker locus in contemporary samples of hard winter and soft red winter wheat relative to samples of Chinese accessions from a $R h t 8$-rich geographic region, and to compare coleoptile elongation in the presence or absence of Rht8 determined by the Xgwm 261 marker. The 165-bp (primarily hard winter wheats) and the 174-bp (primarily soft red winter wheats) alleles of $\mathrm{Xgwm} 261$ were most frequent. About $8 \%$ of all U.S. accessions carried the 192-bp allele diagnostic for Rht8, compared with $64 \%$ of the Chinese accessions. Coleoptile length varied among accessions from 4.4 to $11.4 \mathrm{~cm}$. Frequency distributions for 192- and non-192-bp genotypes showed no advantage of the 192bp allele to coleoptile elongation. None of the 192-bp genotypes from the Great Plains showed greater coleoptile length than 'TAM 107', a hard red winter cultivar without $R \boldsymbol{h t} 8$ often chosen over contemporary cultivars for its greater emergence capacity with deeper seed placement. Since coleoptile elongation may be controlled by several quantitative trait loci, identifying only the presence of 192-bp allele of Xgwm 261 may be misleading if the primary motivation for its deployment is to increase coleoptile length in a semidwarf plant type.
\end{abstract}

$I^{N}$ ENVIRONMENTS where successful crop establishment is hindered by poor seedling emergence, wheat breeders are challenged by the need to improve coleoptile elongation in the presence of GA3-insensitive dwarfing genes, which tend to restrict it. Although coleoptile elongation is under polygenic control (Singhal et al., 1985; Rebetzke et al., 1999, 2001), a major QTL that maps directly to the Rht (Reduced height)-B1 locus (formerly Rht1) and another QTL on chromosome arm 4BL may account for the majority of genotypic variation in coleoptile length measured at 11 to $19^{\circ} \mathrm{C}$ (Rebetzke et al., 2001). This restriction provides an incentive to winter wheat breeding programs to use alternative dwarfing genes in the low-precipitation dryland regions

G-H. Bai, 4008 Throckmorton Hall, USDA-ARS, Department of Agronomy, Kansas State University, Manhattan, KS 66506; M.K. Das, B.F. Carver, X. Xu, and E.G. Krenzer, 368 Agricultural Hall, Department of Plant and Soil Sciences, Oklahoma State University, Stillwater, OK 74078. Research funded by the Oklahoma Wheat Research Foundation and the Oklahoma Agricultural Experiment Station. Mention of trade names or commercial products in this article is solely for the purpose of providing specific information and does not imply recommendation or endorsement by the U.S. Department of Agriculture. Received 25 June 2003. *Corresponding author (gbai@agron. ksu.edu).

Published in Crop Sci. 44:1187-1194 (2004).

(c) Crop Science Society of America

677 S. Segoe Rd., Madison, WI 53711 USA of the Great Plains and Pacific Northwest, where deep seed placement is needed to reach moist soil to initiate germination (Budak et al., 1995; Schillinger et al., 1998).

In the southern and central Great Plains, there is further incentive for long coleoptile because winter wheat is seeded early as a dual-purpose crop for forage and grain production. Deep seed placement and reduced coleoptile elongation in the predominately hot soils can combine to have a potentially devastating impact on stand establishment (Stockton et al., 1996). Historically, earlier-planted wheat produces lower grain yield than later-planted grain-only wheat (Epplin et al., 2000). Hence, poor stand establishment translates, in part, to reduced profitability of both components of the dual-purpose system, estimated to account for the majority of the area seeded in Oklahoma (Epplin et al., 1998).

Two strategies may be followed to achieve adult-plant height reduction without the negative consequences of reduced coleoptile elongation. One might be to generate populations void of $R h t-B 1 b$ (formerly $R h t 1$ ) and $R h t$ $D 1 b$ (formerly $R h t 2$ ) and select phenotypically for minor height-suppressing genes. Removal of these genes in bread wheat near-isogenic lines produced only minor increases (less than 28\%) in height, but substantially greater increases (up to $65 \%$ ) in coleoptile length (Trethowan et al., 2001). Independent expression of plant height and coleoptile length in non-Rht1 or non$R h t 2$ populations should allow divergent selection responses for these traits, i.e., shorter height, longer-coleoptile genotypes, in the same population (Rebetzke et al., 1999; Trethowan et al., 2001). A second strategy might be to introduce GA-responsive dwarfing genes, such as $R h t 8$, Rht 9 , and $R h t 12$, that may not reduce coleoptile elongation, though their phenotypic detection may be more challenging (Worland et al., 1994; Worland and Snape, 2001).

Following its debut in the Japanese cultivar Akakomugi, a relatively weak height-reducing allele at the Rht8 locus gained attention from southern European, Russian, and Chinese breeding programs targeting semidwarf stature in lieu of GA-insensitive $R h t$ genes. In near-isogenic backgrounds, this allele has shown moderate reductions in plant height, and additional reductions when combined with the closely linked photoperiodinsensitive, height-reducing gene, Ppd-D1 (Worland et al., 1998). Other GA-responsive genes, Rht 9 and Rht12, have not gained a similar level of popularity because of their negative associations with grain yield (Worland and Snape, 2001). The discovery of a microsatellite marker, Xgwm 261, $0.6 \mathrm{cM}$ from the Rht8 locus has made it possible to detect allelic variants that confer varying degrees of height reduction or promotion. The 192-bp allele of Xgwm 261 is indicative of the more 
commercially favorable $R h t 8$ allele, while the other alleles of Xgwm 261 marker locus are considered associated with various levels of height promotion (Korzun et al., 1998).

The agronomic value of $R h t 8$ and the discovery of its diagnostic marker have ignited breeders' interest in $R h t 8$ as an alternative dwarfing gene. As expected, Rht 8 is concentrated in regions where it was first introduced and subsequently spread through Italy to additional countries: Bulgaria, Greece, Yugoslavia, Ukraine, and China (Worland et al., 1998, 2001). The distribution of Rht8 in North American gene pools is not extensively characterized, though the gene has been found in a few cultivars (Ahmad and Sorrells, 2002). A more extensive survey of the Great Plains gene pool is justified given that cultivars featuring $R h t 8$ as the primary dwarfing gene might potentially have greater success in earlyplanted management systems or in High Plains dryland environments.

Breeding programs throughout the Great Plains occasionally introduce germplasms from Europe and Asia where $R h t 8$ is known to occur, if not predominate relative to other dwarfing genes. Thus, we hypothesized that the Xgwm 261 192-bp allele diagnostic of $R h t 8$ could be identified in advanced breeding lines and cultivars originating from European programs. Because soft red winter (SRW) wheat is sometimes used by hard winter wheat breeders in interclass hybridizations, this germplasm pool might serve as a more useful Rht 8 provider than germplasms from international programs. The objectives of this study were to (i) determine allelic distributions at the Xgwm 261 locus in contemporary samples of hard winter and SRW wheat, (ii) compare those distributions to a genotypic sample (Chinese landraces and cultivars) from a Rht8-rich region of the world, and (iii) compare coleoptile elongation in the presence and absence of the Xgwm 261 192-bp allele.

\section{MATERIALS AND METHODS}

\section{Plant Materials}

The study involved a primary set of 135 wheat accessions, mostly from the USA and China. The U.S. accessions included 80 hard winter wheat (primarily hard red winter, HRW) and 25 SRW experimental lines and cultivars. Selection of contemporary hard winter wheat cultivars was based on their commercial importance to the southern and central Great Plains. Additionally, we evaluated a historical set of $12 \mathrm{HRW}$ cultivars previously assessed for adaptation to a dual-purpose system (Khalil et al., 2002), and all hard winter experimental lines and check cultivars tested in the 2001 Southern Regional Performance Nursery. The SRW genotypes included experimental lines from the University of Illinois and some entries submitted to the 1997 Uniform Eastern Soft Red Winter Wheat Nursery and the 1997 Five-State Advanced Nursery. Pedigree and origin of a total of 135 accessions are listed in Appendix 1.

Accessions from other sources were selected based on their putative $R h t 8$ genotype, including the Italian cultivars Mara and Funo, and the experimental lines ARS96329, ARS96339, and ARS96342 (Schillinger et al., 1998). Others were selected on the basis of their coleoptile elongation potential, including the Australian experimental lines PH179 and PH18 (G.J. Rebetzke, personal communication, 1997) and a selection from
'Sturdy', TX9129-962 (K. Porter, personal communication, 1998).

\section{Molecular Marker Analysis}

DNA was isolated from bulked leaves of two to three seedlings by the CTAB procedure (Saghai-Maroof et al., 1984). Microsatellite marker Xgwm 261 from chromosome 2DS was analyzed for all accessions in an $\mathrm{IR}^{2}-4200$ DNA sequencer (LI-COR Inc., Lincoln, NE) by labeling one primer with an infrared (IR) fluorescence dye. Each $10 \mu \mathrm{L}$ PCR sample contained $30 \mathrm{ng}$ DNA, $1 \times$ PCR buffer, $0.25 \mathrm{~m} M$ dNTP, $2.5 \mathrm{~m} M$ $\mathrm{MgCl}_{2}, 0.5$ pmol each of labeled and unlabeled SSR primers, and 1 unit of Taq polymerase. The following touchdown thermal profile was used for SSR amplification: $5 \mathrm{~min}$ at $95^{\circ} \mathrm{C}, 5$ min at $68^{\circ} \mathrm{C}$, and $1 \mathrm{~min}$ at $72^{\circ} \mathrm{C}$ for five cycles, in which the annealing temperature was lowered by $2^{\circ} \mathrm{C}$ per cycle; five more cycles with 2 min annealing time in which the temperature was lowered by $2^{\circ} \mathrm{C}$ per cycle; and 25 cycles in which the annealing temperature remained constant at $50^{\circ} \mathrm{C}$. Five minutes at $72^{\circ} \mathrm{C}$ was used for the final extension. Molecular sizes of the SSR fragments were determined by comparison with the DNA size standard (LI-COR Inc., Lincoln, NE) by RFLPscan software (Scanalitics, Inc., Fairfax, VA).

\section{Coleoptile Length Measurement}

Seeds for the coleoptile length measurements were obtained from greenhouse-grown plants and germinated $60 \mathrm{~d}$ after harvesting. Coleoptile length was measured following the method of Hakizimana et al. (2000) with some modifications. Fifteen uniform seeds per accession were spaced $1 \mathrm{~cm}$ apart and about $7 \mathrm{~cm}$ from the bottom of a germination towel (no. 76 germination paper; Anchor Paper Co., St. Paul, MN). Each towel contained a different accession. The towel was folded at about $5 \mathrm{~cm}$ from the bottom, placed inside wax paper, rolled loosely, and secured with a rubber band. The wrapped towels were arranged vertically on a metal rack, set in distilled water to wet the germination towels thoroughly, and then drained of excessive water. The samples were covered with black plastic and placed in a cold room at $4^{\circ} \mathrm{C}$ for $2 \mathrm{~d}$ to interrupt any dormancy. The samples were incubated in a growth chamber at $100 \%$ relative humidity and $15^{\circ} \mathrm{C}$ for $7 \mathrm{~d}$, followed by $6 \mathrm{~d}$ at $20^{\circ} \mathrm{C}$. This procedure was conducted six times for all accessions, with re-randomization of entries in each replicate.

Means comparisons were performed for coleoptile length between allelic classes of Xgwm 261 using a $t$ test. Frequency distributions for coleoptile length were compared among allelic classes of Xgwm 261 (192-bp, 165-bp, or all allelic classes excluding 192-bp allele) on the basis of the Kolmogorov-Smirnov test (Steel et al., 1997).

\section{RESULTS AND DISCUSSION Allelic Variation at Xgwm 261 Locus}

Microsatellite Xgwm 261 was highly polymorphic among the 135 accessions examined in this study. The microsatellite primers amplified nine SSR fragments that varied in size from 165 bp to 212 bp (Table 1). One hundred sixteen accessions amplified a single fragment, 15 accessions (13 from the HWW class) amplified two SSR fragments of different sizes, and four accessions from the HRW class amplified three SSR fragments of different sizes. Among these microsatellite alleles, the 165-bp fragment occurred with greatest frequency (39\%), followed by 174-bp (17\%), 192-bp (16\%), 210-bp (14\%), and 197-bp (10\%) fragments (Table 1). The 184-, 194-, 202-, and 212-bp fragments were most uncommon $(<3 \%)$. 
Table 1. Distribution of allelic variants for Xgwm 261 and coleoptile length among 135 wheat accessions.

\begin{tabular}{|c|c|c|c|c|c|c|c|c|c|c|c|c|}
\hline \multirow[b]{2}{*}{ Accession type $\dagger$} & \multirow{2}{*}{$\begin{array}{l}\text { Number of } \\
\text { accessions } \$\end{array}$} & & \multicolumn{6}{|c|}{ Size of Xgwm 261 fragments (bp) } & \multicolumn{4}{|c|}{ Coleoptile length } \\
\hline & & & 165 & 174 & 192 & 197 & 210 & Other§ & Mean & Min & Max & SD \\
\hline & & & & & -1 & ber - & & ${ }_{5}$ & 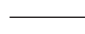 & $-c$ & & \\
\hline \multirow[t]{2}{*}{ USA } & HWW & 80 & 53 & 4 & 6 & 10 & 22 & 6 & 7.8 & 4.4 & 10.2 & 0.9 \\
\hline & SRW & 25 & 5 & 18 & 2 & & & 1 & 8.3 & 6.1 & 10.9 & 1.0 \\
\hline \multirow{2}{*}{ China } & cultivars & 17 & 2 & 2 & 13 & & & 1 & 9.6 & 6.4 & 11.4 & 1.4 \\
\hline & landraces & 5 & & & 1 & 1 & & 3 & 10.6 & 9.8 & 11.2 & 0.7 \\
\hline \multirow{5}{*}{ Other genotypes } & ARS lines I & 3 & & 3 & & & & & 9.9 & 9.2 & 10.3 & 0.6 \\
\hline & PH lines\# & 2 & 1 & & $\mathbf{1}$ & & & & 7.4 & 5.9 & 8.8 & \\
\hline & Funo & 1 & & & 1 & & & & 8.2 & & & \\
\hline & Mara & 1 & & & 1 & & & & 7.9 & & & \\
\hline & TX9129 & 1 & 1 & & & & & & 9.3 & & & \\
\hline \multirow{4}{*}{ Coleoptile length $(\mathrm{cm})$} & mean & & 7.9 & 8.5 & 8.8 & 7.9 & 7.9 & 8.3 & & & & \\
\hline & $\min$ & & 4.4 & 6.5 & 6.4 & 7.1 & 6.9 & 6.1 & & & & \\
\hline & $\max$ & & 10.6 & 11.2 & 11.4 & 9.8 & 10.6 & 11.3 & & & & \\
\hline & SD & & 1.1 & 1.3 & 1.5 & 0.7 & 0.7 & 1.6 & & & & \\
\hline
\end{tabular}

$\dagger$ HWW = Hard winter wheat, comprised of hard red winter and hard white winter classes; SRW = soft red winter class.

Total no. of Xgwm 261 genotypes may exceed the number of accessions due to within-accession heterogeneity at the marker locus.

$\$$ Among these 11 accessions, one showed 184-bp, three showed 194-bp, two showed 202-bp, and five showed 212-bp alleles.

Il ARS lines include ARS96329, ARS96339 and ARS96342 (Schillinger et al., 1998).

\# PH lines are PH 18 and PH 179 from Australia.

Among the nine SSR fragments, eight were detected in the hard winter accessions, and only four fragments were detected in each of the other accession types, indicating that the polymorphic level of microsatellite Xgwm 261 was highest among the hard winter accessions in this study.

Seven of the nine Xgwm 261 alleles were the same as those reported by Ahmad and Sorrells (2002) and Worland et al. (2001). The 165-, 174-, and 192-bp fragments were more common among the three surveys, including this one. The 210-bp allele only appeared in the HRW class and was not reported in previous studies. Seven other alleles (195-, 196-, 201-, 203-, 205-, and 215bp fragments) reported by Worland et al. (2001) and three alleles (180-, 198-, and 200-bp fragments) reported by Ahmad and Sorrells (2002) were not found in our samples. The 184- and 212-bp fragments detected in four U.S. HRW accessions and two Chinese SRW accessions represent unreported alleles of Xgwm 261.

The majority of the 80 hard winter accessions contained the 165-bp allele, whereas the majority of the 25 SRW accessions contained the 174-bp allele. These two alleles prevailed in more limited samples of U.S. wheat cultivars (Worland et al., 2001; Ahmad and Sorrells, 2002), but differentiation of the predominant U.S. hard and soft wheat classes at Xgwm 261 was not possible in those surveys. These alleles were also found in the highest frequency among CIMMYT-derived semidwarf wheat accessions (165 bp) and in United Kingdom, German, and French wheat gene pools (174 bp) (Worland et al., 1998). Their worldwide prevalence in regions outside of southern Europe, Japan, and China is attributed to a possible compensatory effect on plant stature in the presence of GA-insensitive Rht genes and photoperiodinsensitive genes (Worland et al., 1998). Their hypothesis may also explain the dominance of the stronger height promoting 165-bp allele among predominately photoperiod-insensitive winter wheat cultivars adapted to the arid environment of the Great Plains, where extreme height reduction would be unacceptable. We found the 165-bp allele consistently among ancestors of modern Great Plains cultivars, such as 'Turkey', 'Khar- kof', 'Triumph 64', and 'Scout 66'. In addition, the 210bp allele only appeared in modern Great Plains cultivars and formed the second largest genotypic group in the class, suggesting this allele may offer some selection advantage to modern cultivars in this region.

The diagnostic marker allele for Rht8 (192 bp) was found in only six HRW accessions and two SRW accessions, representing $6 \%$ of the total accessions in both classes. From the HRW class, accessions carrying the 192-bp allele included 'TX97D6377', 'G97380', and 'HG-9'. Cultivars 2163, Ok102, and 2137 (with 50\% of its parentage from 2163) were heterogeneous for the 192-bp allele and either the 174- or 165-bp allele. Though present in low frequency, the germplasm with 192-bp allele appears to be scattered among hard winter wheat breeding programs in the Great Plains. In the SRW class, the 192-bp allele was limited to two highly related experimental lines from Illinois, IL 94-2426 and IL 95-2909 (also heterogeneous for the 165-bp allele). However, on the basis of the available pedigrees, we are neither able to determine the origin of $R h t 8$ in these U.S. accessions carrying the 192-bp allele nor affirm the presence of $R h t 8$ in these accessions because the 192-bp allele is a linked marker to $R h t 8$, not part of the gene.

In contrast to the two U.S. gene pools, the majority (76\%) of Chinese accessions contained the 192-bp allele (Table 1), which is consistent with Worland et al. (2001). Most of these accessions had Funo or a relative of Funo in their pedigrees, indicating a high possibility of $R h t 8$ in these accessions. These results confirm the value of Chinese germplasm as a potential Rht8 donor. Of particular interest was the Chinese cultivar, Sumai 3, which we found to contain the 192-bp allele contributed from Funo. If not by design, then certainly by accident, $R h t 8$ introgression has already commenced in many wheat breeding programs that targeted Sumai 3 as a source of Type II resistance to Fusarium head blight caused by Fusarium graminearum Schwake [teleomorph Gibberella zeae (Schwein.)] (Bai et al., 2003). We would expect this to be the case in U.S. wheat because of introduction of Sumai 3 as a scab resistant parent in winter or spring wheat breeding programs. 
We evaluated several other accessions thought to have $R h t 8$ or long coleoptile potential (Table 1, "Other genotypes"). Two Italian cultivars, Funo and Mara, and one Australian line having Mara as one of its parents, PH 18, contained the 192-bp allele. We could not confirm that three soft white winter experimental lines, ARS96329, ARS96339, and ARS96342, contained the 192-bp allele, which were previously claimed to have Rht8 (Schillinger et al., 1998). This could result either from the absence of $R h t 8$ in these selections, or from recombination between $R h t 8$ and the marker locus. Although TX9129 was selected from Sturdy for its greater coleoptile elongation, that characteristic is not attributable to Rht8.

\section{Coleoptile Elongation and Xgwm 261 192-bp Allele}

Coleoptile length was measured with moderate repeatability among the 135 accessions, as estimated by the intraclass correlation coefficient of $0.40 \pm 0.04$. Hakizimana et al. (2000) reported slightly higher repeatability of 0.6 to 0.7 among $15 \mathrm{HRW}$ genotypes. A $7.0-\mathrm{cm}$ range in coleoptile length was found among individual accessions, and their mean was $8.2 \mathrm{~cm}$. The longest coleoptile was $11.4 \mathrm{~cm}$ for Chinese cultivars Wannian 2 and F 60096. The shortest was $4.4 \mathrm{~cm}$ for HRW cultivar '2180'. Chinese accessions tended to have longer coleoptiles than U.S. accessions, yet considerable overlap occurred among U.S. and Chinese cultivars (Table 1). Genotypes with the Xgwm 261 locus varied in mean coleoptile length from $7.9 \mathrm{~cm}$ (genotypes carrying 165-, 197-, and 210-bp alleles) to $8.8 \mathrm{~cm}$ (192-bp genotypes).

Frequency distributions for coleoptile length were generated for 192-bp genotypes, all genotypes lacking the 192-bp allele, and for the more common genotype with the 165-bp allele (Fig. 1). Only the non-192-bp distribution departed from normality $(P<0.01$, Shapiro-Wilk test). However, these distributions did not differ significantly on the basis of the Kolmogorov-Smirnov statistic. An obvious association between greater coleoptile length and the presence of the 192-bp allele could not be detected from these results and visual examination of the distributions. Several accessions that contained the 192-bp allele had no greater coleoptile
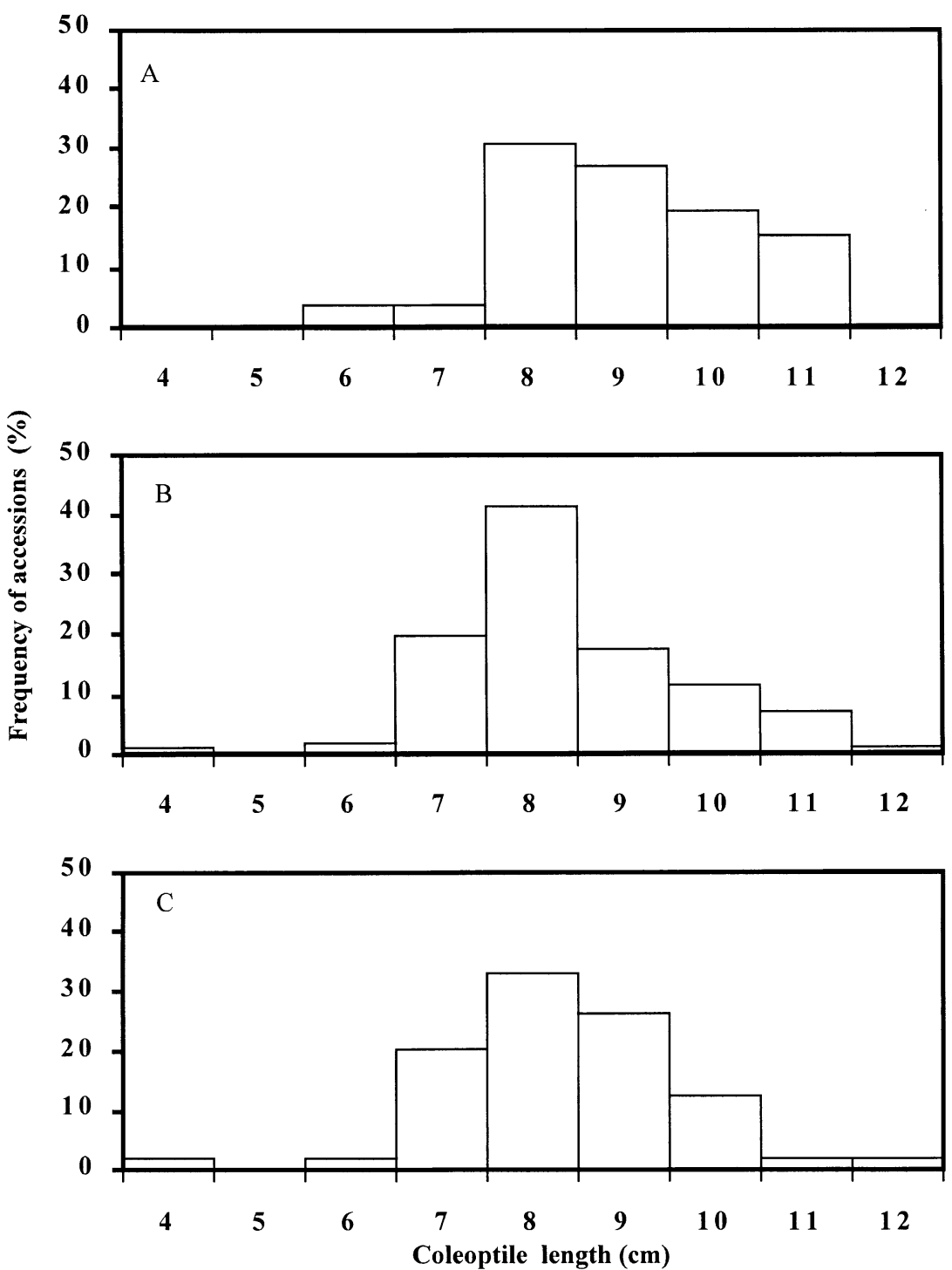

Fig. 1. Distributions for coleoptile length of wheat accessions containing only the 192-bp allele $(A, n=26)$, of all accessions not containing the 192-bp allele (B, $n=121)$, or of accessions strictly containing the 165 -bp allele $(\mathrm{C}, n=46)$ of the microsatellite marker Xgwm 261. 
length than those that did not (Fig. 1), especially those in the HRW and other genotypes classes (Fig. 1).

Restricting marker-genotype comparisons to accessions of a common type revealed no significant benefit of $R h t 8$ to coleoptile elongation for U.S. or Chinese modern cultivars (Table 2). Among the 25 accessions with the 192-bp allele, 16 had coleoptile lengths no greater than the value recorded for TAM $107(9.6 \mathrm{~cm})$, whereas 22 accessions had coleoptile lengths no greater than Scout $66(10.6 \mathrm{~cm})$. These non-Rht8 cultivars, in which Scout 66 is standard height and TAM 107 is semidwarf, are often chosen in the Great Plains over modern semidwarf cultivars for their greater coleoptile length and capacity for emergence with deeper seed placement. None of the 192-bp HRW genotypes exceeded Scout 66 or TAM 107 in coleoptile length.

A plausible argument for the lack of a detectable advantage in coleoptile elongation is that other heightreducing genes already present in modern $R h t 8$ genotypes offset or mask any potential benefit of $R h t 8$. For example, coleoptile length in Dwarf Sumai 3 (Sumai $3 * 2 /$ 'Tom Thumb') was reduced by $>4 \mathrm{~cm}$ compared with Sumai 3 (6.4 vs. $10.6 \mathrm{~cm})$, but both accessions contained the 192-bp allele. Identifying only the presence of the 192-bp allele may be misleading if the primary motivation for its deployment is to increase coleoptile elongation in a semidwarf plant type. It is recommended that selection for Rht8 using the 192-bp Xgwm 261 marker can be attempted in the absence of GA-insensitive $R h t$ genes, followed by selection for minor genes
Table 2. Pairwise means comparisons for coleoptile length $(\mathrm{cm})$ of wheat accessions possessing the Xgwm 261 192-bp allele (Rht8) versus all those without the 192-bp allele (non-Rht8) or strictly those possessing the 165 -bp allele.

\begin{tabular}{|c|c|c|c|c|}
\hline \multirow[b]{2}{*}{ Accession type $\dagger$} & \multicolumn{3}{|c|}{ Xgwm 261 genotype $(b p) \ddagger$} & \multirow[b]{2}{*}{$t$ Tes } \\
\hline & 192 & Minus 192 & 165 & \\
\hline & & $\mathbf{c m}-$ & - & \\
\hline All§ & 9.0 & 8.3 & & *** \\
\hline All & 9.0 & & 8.3 & $*$ \\
\hline HWW & 8.0 & 7.8 & & NS \\
\hline HWW & 8.0 & & 7.9 & NS \\
\hline SRW & 9.2\# & 8.2 & & NS \\
\hline Chinese cultivars & 9.5 & 10.4 & & NS \\
\hline Chinese landraces & 11.0 & 10.5 & & NS \\
\hline
\end{tabular}

* Indicates $\boldsymbol{t}$ test significant at $\boldsymbol{P}=\mathbf{0 . 0 5}$.

** Indicates $\boldsymbol{t}$ test significant at $\boldsymbol{P}=\mathbf{0 . 0 1}$.

NS $=$ nonsignificant $(P>0.05)$.

$\dagger$ HWW $=$ Hard winter wheat, comprised of HRW and hard white classes; SRW $=$ soft red winter class.

$¥$ Only those accessions homogeneous for the 192 -bp or 165 -bp alleles were included in the genotype means; accessions heterogeneous for alleles other than 192-bp were included in the minus-192-bp mean.

$\S$ All includes 80 of HWW accessions, 25 of SRW accessions, 22 of Chinese accessions, and 8 of other accessions as listed in Appendix Table 1.

\# Based on only one homogeneous accession.

to achieve the desired level of plant height. Though $R h t 8$ appears to be accessible in other gene pools, this study supports additional genotyping of Great Plainsadapted materials with special emphasis on detection of $R h t 8$ in a standard-height genetic background. On the basis of the cultivars we screened, Midwestern SRW genotypes do not appear to offer any advantage over locally adapted materials as an $R h t 8$ donor.

Appendix 1. Allelic identity for microsatellite Xgwm 261 and mean coleoptile length of 135 wheat accessions.

\begin{tabular}{|c|c|c|c|c|c|}
\hline Cultivar & Origin & Source $\dagger$ & Pedigree & $\begin{array}{l}\text { Fragment } \\
\text { size (bp) }\end{array}$ & $\begin{array}{c}\text { Mean } \\
\text { coleoptile } \\
\text { length } \nleftarrow\end{array}$ \\
\hline \multicolumn{6}{|c|}{ Hard winter wheat } \\
\hline 2137 & USA & $\begin{array}{l}\text { PI 592444 } \\
\text { Pioneer, KSU }\end{array}$ & W2440/W9488A//2163 & 165,192 & 6.4 \\
\hline 2157 & USA & Pioneer, KSU & Caprock/B 86//Sc 3212 & 165 & 7.4 \\
\hline 2158 & USA & Pioneer & Unknown & 165 & 9.1 \\
\hline 2163 & USA & Pioneer, KSU & $\begin{array}{l}\text { Pioneer line W558/5/Etoile de Choise//Thorne/Clarkan/3/ } \\
\text { CI15342/4/Pur 4946A4-18-2 }\end{array}$ & 174, 192 & 6.5 \\
\hline 2174 & USA & Pioneer, OSU & IL 71-5662/PL 145//2165 & 165 & 8.6 \\
\hline 2180 & USA & PI 532912, Pioneer & TAM W-101/Pioneer W603//Pioneer W558 & 165 & 4.4 \\
\hline Above & USA & CSU & TAM $110 * 4 / F S 2$ & 165 & 8.4 \\
\hline AP502CL & USA & AgriPro, CSU & TXGH12588-26*4/FS2 & 165 & 9.7 \\
\hline Chisholm & USA & PI 486219, OSU & Sturdy sib/Nicoma & 165 & 7.8 \\
\hline CO970498 & USA & CSU & Ogallala/Halt & 210 & 8.2 \\
\hline C0970531 & USA & CSU & Ike/Halt & 210 & 8.2 \\
\hline $\mathbf{C O 9 7 0 5 4 7}$ & USA & CSU & Ike/Halt & 165,210 & 6.9 \\
\hline CO970940 & USA & CSU & Yuma/T-57//Lamar/3/4*Yuma/4/NEWS16 & 165 & 7.1 \\
\hline Coronado & USA & AgriPro & Mustang/W80-425//COMP76B-1-84-1/SW74-8A-47 & 212 & 6.8 \\
\hline Custer & USA & OSU & F29-76/TAM 105//Chisholm & 165 & 7.6 \\
\hline Cutter & USA & AgriPro & KS84063-9-39-3//TAM-200/W81-296 & 210 & 7.7 \\
\hline Dumas & USA & AgriPro & F2SPS-102/TAMW-101//RPB/Mustang/W80-425/Comp. Sel. & 165 & 6.9 \\
\hline Enhancer & USA & Goertzen Seed & HT43H-331-9 (Nebraska winter hardy selection) & 165 & 9.2 \\
\hline G1878 & USA & Goertzen Seed & Hawk//Sturdy/Plainsman V & 165 & 9.2 \\
\hline G97209 & USA & Goertzen Seed & Karl 92/G525/Arlin & 165 & $\mathbf{7 . 7}$ \\
\hline G97380 & USA & Goertzen Seed & GSR2500/Plainsman V//KARL92 & 192 & 7.4 \\
\hline HG-9 & USA & $\begin{array}{l}\text { Hardeman Grain } \\
\text { \& Seed }\end{array}$ & TAM 200 outcross selection & 192 & 9.1 \\
\hline Ike & USA & PI 574488 KSU & Dular/Eagle//2* Cheney/Larned/3/Colt & 212 & 7.7 \\
\hline Intrada & USA & PI 631402 OSU & Rio Blanco/TAM 200 & 197 & 8.1 \\
\hline Jagger & USA & PI 593688 KSU & KS82W418/Stephens & 165,212 & 7.5 \\
\hline Kalvesta & USA & Goertzen Seed & Oelson/Hamra//Australia215/3/Karl & 165 & 7.8 \\
\hline
\end{tabular}

Continued next page. 
Appendix 1. Continued.

\begin{tabular}{|c|c|c|c|c|c|}
\hline Cultivar & Origin & Source $\dagger$ & Pedigree & $\begin{array}{l}\text { Fragment } \\
\text { size (bp) }\end{array}$ & $\begin{array}{c}\text { Mean } \\
\text { coleoptile } \\
\text { length } \%\end{array}$ \\
\hline Karl 92 & USA & PI 564245, KSU & Plainsman V/3/Kaw/Atlas 50//Parker $* 5 /$ Agent & 165,210 & 7.1 \\
\hline Kharkof & Ukraine & PI 5641 & Landrace from Ukraine & 165 & 7.5 \\
\hline KS920709-B-5-2 & USA & KSU & ABI 86*3414/X84W063-9-39-2//Karl 92 & 210 & 7.5 \\
\hline KS920946-B-15-2 & USA & KSU & T67/X84W063-9-45//Karl 92 & 210 & 7.7 \\
\hline KS98HW151-6 & USA & KSU & Arlin//TA2460/*3 TAM107 & 165 & 9.1 \\
\hline KS98HW220-5 & USA & KSU & Arlin/Yuma & 165 & 7.4 \\
\hline Lakin & USA & PI 617032 KSU & KS89H130/Arlin & 165 & 7.8 \\
\hline Lockett & USA & PI 604245 TAM & TX86V1540/TX78V2430-4 & 165 & 8.2 \\
\hline NE97465 & USA & UNL & SD3055/KS88H164//Colt*2/Patrizanka & 210 & 10.2 \\
\hline NE97V121 & USA & UNL & N87V106/OK88767 & 165,210 & $\mathbf{7 . 7}$ \\
\hline NE98466 & USA & UNL & KS89H50-4/3/Brl//Sxl/Benn & 210 & 7.0 \\
\hline NE98564 & USA & UNL & Colt/Cody//Yuma & 165,210 & 7.3 \\
\hline NE98632 & USA & UNL & Niobrara/5/Aiv/Nbr/Bolal//Hiplains/3/Lov6/4/Redland & 165 & 7.3 \\
\hline NI98439 & USA & UNL & Benn/BRL//X10927 592-1-5 & 165 & 7.7 \\
\hline NW97S218 & USA & $\begin{array}{l}\text { USDA-ARS } \\
\text { Lincoln }\end{array}$ & KS85W663-1-1/Karl 92 & 210 & 7.6 \\
\hline NW97S278 & USA & $\begin{array}{l}\text { USDA-ARS } \\
\text { Lincoln }\end{array}$ & Pronghorn/Arlin & 197 & 7.2 \\
\hline Ogallala & USA & AgriPro & TX81V6187//OK711252/W76-1226 & 197,210 & 7.6 \\
\hline Ok102 & USA & OŜU & 2174/Cimarron & 165,192 & 7.5 \\
\hline OK93P656-RMH3299 & USA & OSU & W0405D/HGF112//W7469C/HCF012 & 165 & 6.6 \\
\hline OK94P549-99-6704 & USA & OSU & HBY756A/Siouxland//2180 & 202 & 7.6 \\
\hline OK96705-99-6745 & USA & OSU & 2180/OK88803//Abilene & 165 & 7.0 \\
\hline OK96717-99-6756 & USA & OSU & Abilene/2180//Chisholm & 165 & 7.7 \\
\hline OK98680 & USA & OSU & Odessa 06/Mesa & 212 & 7.6 \\
\hline Onaga & USA & AGSECO & & 165 & 7.7 \\
\hline Scout 66 & USA & CItr 13996 UNL & Composite of 85 selections from Scout, CItr 13546 & 165,210 & 7.9 \\
\hline T001X & USA & Trio Seed & Hybrid & $165,174,210$ & 7.9 \\
\hline T002X & USA & Trio Seed & Hybrid & $165,174,210$ & 7.3 \\
\hline T003X & USA & Trio Seed & Hybrid & $165,174,210$ & 7.5 \\
\hline T122 & USA & Trio Seed & Tecumseh/5627//T91 & 165 & 7.3 \\
\hline TAM 105 & USA & CItr 17826, TAM & 'short wheat' Sturdy composite bulk selection & 165 & 7.8 \\
\hline TAM 107 & USA & PI 495594 TAM & TAM $105 * 4 /$ Amigo & 165 & 9.6 \\
\hline TAM 110 & USA & PI 595757 TAM & (TAM $105 * 4 /$ Amigo) $* 5 /$ Largo & 165 & 9.9 \\
\hline TAM 111 & USA & TAM & TAM 107//TX78V3620/CTK78/3/TX87V1233 & 194 & 8.8 \\
\hline TAM 202 & USA & PI 561933 TAM & Siouxland outcross & 197 & 7.9 \\
\hline TAM 302 & USA & PI 605910 TAM & Probrand 812/Caldwell//TX86D1310 (TAM 300 sib) & 165 & 8.0 \\
\hline TAM W-101 & USA & CItr 15324, TAM & Norin 10/3/Nebraska 60//Mediterranean/Hope/4/Bison & 165,210 & 7.3 \\
\hline Thunderbolt & USA & AgriPro & OK711252A/W76-1226//KS90WGRC10 & 165 & 8.2 \\
\hline Tomahawk & USA & AgriPro & Ironstraw S4 & 210 & 7.3 \\
\hline Tonkawa & USA & OSU & F29-76/TAM 105//Chisholm & 165 & 7.1 \\
\hline Trego & USA & PI 612576 KSU & KS87H325/Rio Blanco & 197 & 7.1 \\
\hline Triumph 64 & USA & CItr 13679 OSU & $\begin{array}{l}\text { Danne Beardless Blackhull/3/Kanred/Blackhull//Florence/4/ } \\
\text { Kanred/Blackhull//Triumph }\end{array}$ & 165 & 9.2 \\
\hline Turkey & Ukraine/Russia & & Landrace & 165 & 8.9 \\
\hline TX 95A1161 & USA & TAM & TAM W-101//NE78488/Veery & 165 & 7.5 \\
\hline TX97A0122 & USA & TAM & TX88V4328/TX87V1613//TX87V1233-1 & 165,197 & 7.5 \\
\hline TX97A0219 & USA & TAM & TX71562-6*4/AMI*4//LGO/3/NE86582 & 165,210 & 8.1 \\
\hline TX97A0244 & USA & TAM & TAM $105^{*} 4 /$ AMI $^{*} 5 / / \mathrm{LGO} / 3 /$ Sturdy & 165 & 8.6 \\
\hline TX97D6377 & USA & TAM & HBG026+NE78659*Arkan/2180 & 192 & 7.6 \\
\hline TX97V2838 & USA & TAM & U1254-1-5-2-1/TX81V6582 & 197 & 7.8 \\
\hline TX98D1170 & USA & TAM & TX89D1253 $* 2 /$ TTCC 404 & 165 & 8.3 \\
\hline TX98V9315 & USA & TAM & U1254-4-7-2/Dong Xie 4 & 197 & 8.1 \\
\hline TX98V9618 & USA & TAM & U1254-1-8-1-1/TAM-202 & 197 & 8.0 \\
\hline TX98V9930 & USA & TAM & U1254-7-9-2-1/TX86A5616 & $165,197,210$ & 7.3 \\
\hline Venango & USA & Goertzen Seed & HBE 1066-105/HBF0551-131 & 210 & 8.1 \\
\hline \multirow[t]{2}{*}{ Vona } & USA & CItr 17441, CSU & II 21183/CO 652363//Lancer/KS 62136 & 165 & 6.6 \\
\hline & & & $\underline{\text { Soft red winter wheat }}$ & & \\
\hline Bacup & USA & PI 596533 & Nuy Bay/Pioneer 2375//Marshall & 165 & 9.3 \\
\hline Cardinal & USA & Ohio State Univ. & Logan*2/3/Va63-5-12/Logan//Blueboy & 165 & 8.8 \\
\hline Clark & USA & PI 512337 & $\begin{array}{l}\text { Beau Caldwell sib/67137B5-16/4/Sullivan/3/Beau// } \\
\text { 5517B8-5-3-3/Logan }\end{array}$ & 174 & 8.1 \\
\hline Ernie & USA & PI 584525 U M & Pike/M09965/3/Stoddard/Blueboy//Stoddard/D1707 & 174 & 8.6 \\
\hline Foster & USA & PI 593689 UK & $\begin{array}{l}\text { Coker65-20/Arthur/4/Chul* 8CCi/VA68-22-7/Abe/3/VA } \\
\text { 72-54-14/Tyler//Suwon 92/Arthur//Arthur/VA 70-52-2 }\end{array}$ & 174 & 7.6 \\
\hline Freedom & USA & Ohio State Univ. & GR876/OH217 & 165 & 8.5 \\
\hline IL 93-2283 & USA & UI & Tyler/Caldwell//Auburn/Wheeler & 174 & 8.1 \\
\hline IL 94-1549 & USA & UI & Auburn/Ark38-1/Arthur/Blueboy & 174 & 8.6 \\
\hline IL 94-1909 & USA & UI & Fillmore/Amigo//Tyler/Howell & 174 & 7.9 \\
\hline IL 94-2426 & USA & $\mathbf{U I}$ & $\begin{array}{l}\text { Roland/4/Coker 68-15/3/IL69-1751/5/IL 70-2227-1/McNair } \\
\text { 1003/2/Howell }\end{array}$ & 192 & 9.2 \\
\hline IL 94-6280 & USA & UI & Tyler/Caldwell//Auburn/Wheeler & 174 & 8.7 \\
\hline IL 95-1966 & USA & UI & $\begin{array}{l}\text { Tyler/Howell/3/Howell//Oasis/Arkansas38-1/4/Auburn/3/ } \\
\text { Rosen//Arthur/Blueboy }\end{array}$ & 174 & $\mathbf{7 . 0}$ \\
\hline IL 95-2066 & USA & UI & $\begin{array}{l}\text { IN7688G1/3/Caldwell//Spritzer Agrotriticum/LRC40/4/P } \\
\text { 79424H1-20-2-74 }\end{array}$ & 174 & 7.9 \\
\hline
\end{tabular}

Continued next page. 
Appendix 1. Continued.

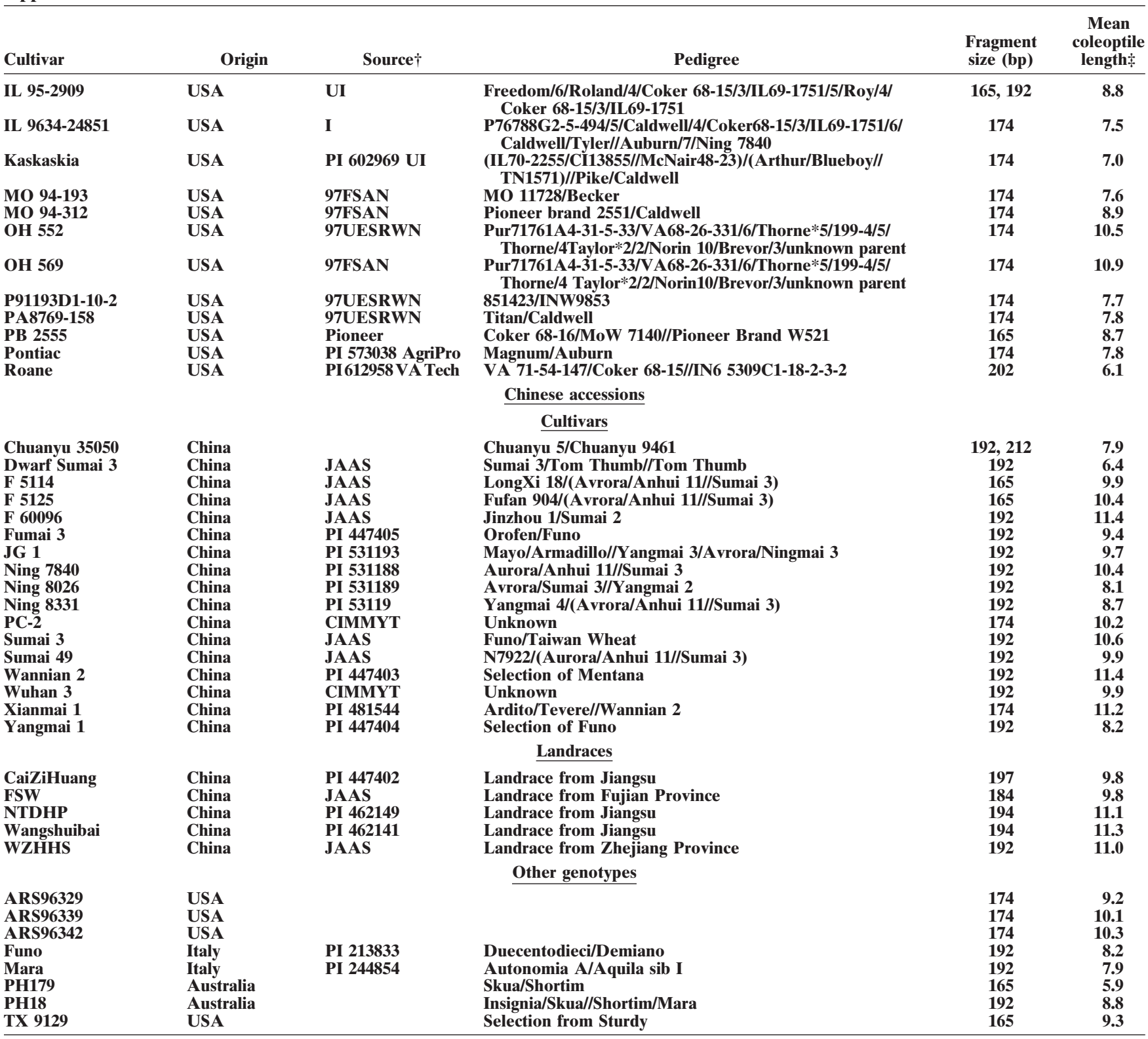

† 97UESRWN = 1997 Uniform Eastern Soft Red Winter Wheat Nursery; 97FSAN = 1997 Five State Advanced Nursery; UK = Univ. of Kentucky; UI = Univ. of Illinois; OSU = Oklahoma State Univ.; KSU = Kansas State Univ.; TAM = Texas A\&M Univ.; CSU = Colorado State Univ.; UNL $=$

Univ. of Nebraska, Lincoln; CIMMYT = International Maize and Wheat Improvement Center; JAAS = Jiangsu Academy of Agricultural Sciences, Nanjing, China.

† Mean of six replicates.

\section{REFERENCES}

Ahmad, M., and M.E. Sorrells. 2002. Distribution of microsatellite alleles linked to Rht8 dwarfing gene in wheat. Euphytica 123:235240.

Bai, G.-H., L.-F. Chen, and G.E. Shaner. 2003. Breeding for resistance to Fusarium head blight of wheat in China. p. 296-317. In K.L. Leonard and W.R. Bushnell (ed.) Fusarium head blight of wheat and barley. APS Press, St Paul, MN.

Budak, N., P.S. Baenziger, K.M. Eskridge, D. Baltensperger, and B. Moreno-Sevilla. 1995. Plant height response of semidwarf and nonsemidwarf wheats to the environment. Crop Sci. 35:447-451.

Epplin, F.M., R.R. True, and E.G. Krenzer, Jr. 1998. Practices used by Oklahoma wheat growers by region. Okla. Curr. Farm Econ. 71(1):14-24.

Epplin, F.M., I. Hossain, and E.G. Krenzer, Jr. 2000. Winter wheat fall-winter forage yield and grain yield response to planting date in a dual-purpose system. Agric. Syst. 63:161-173.

Hakizimana, F., S.D. Haley, and E.B. Turnipseed. 2000. Repeatability and genotype $X$ environment interaction of coleoptile length measurements in winter wheat. Crop Sci. 40:1233-1237.

Khalil, I.H., B.F. Carver, E.G. Krenzer, C.T. MacKown, and G.W. Horn. 2002. Genetic trends in winter wheat yield and test weight under dual-purpose and grain-only management systems. Crop Sci. 42:710-715.

Korzun, V., M.S. Roder, M.W. Ganal, A.J. Worland, and C.N. Law. 1998. Genetic analysis of the dwarfing gene (Rht8) in wheat. Part I. Molecular mapping of Rht 8 on the short arm of chromosome 2D of bread wheat (Triticum aestivum L.). Theor. Appl. Genet. 96:1104-1109.

Rebetzke, G.J., R. Appels, A.D. Morrison, R.A. Richards, G. McDonald, M.H. Ellis, W. Spielmeyer, and D.G. Bonnett. 2001. Quantita- 
tive trait loci on chromosome 4B for coleoptile length and early vigour in wheat (Triticum aestivum L.). Aust. J. Agric. Res. 52: 1221-1234.

Rebetzke, G.J., R.A. Richards, V.M. Fischer, and B.J. Mickelson. 1999. Breeding long coleoptile, reduced height wheats. Euphytica 106:159-168.

Saghai-Maroof, M.A., K.M. Soliman, R.A. Jorgensen, and R.W. Allard. 1984. Ribosomal DNA spacer-length polymorphisms in barley: Mendelian inheritance, chromosomal location, and population dynamics. Proc. Natl. Acad. Sci. USA 81:8014-8018.

Schillinger, W.F., E. Donaldson, R.E. Allan, and S.S. Jones. 1998. Winter wheat seedling emergence from deep sowing depths. Agron. J. 90:582-586.

Singhal, N.C., K.B.L. Jain, and M.P. Singh. 1985. Genetic analysis of coleoptile length and plant height in bread wheat. Cereal Res. Comm. 13:231-237.

Steel, R.G.D., J.H. Torrie, and D.A. Dickey. 1997. Principles and procedures of statistics: A biometrical approach. 3rd ed. McGrawHill.

Stockton, R.D., E.G. Krenzer, Jr., J. Solie, and M.E. Payton. 1996.
Stand establishment of winter wheat in Oklahoma: A survey. J. Prod. Agric. 9:571-575.

Trethowan, R.M., R.P. Singh, J. Herta-Espino, J. Crossa, and M. Van Ginkel. 2001. Coleoptile length variation of near-isogenic Rht lines of modern CIMMYT bread and durum wheats. Field Crops Res. 70:167-176.

Worland, A.J., V. Korzun, M.S. Roder, M.W. Ganal, and C.N. Law. 1998. Genetic analysis of the dwarfing gene Rht8 in wheat. Part II. The distribution and adaptive significance of allelic variants at the Rht8 locus of wheat as revealed by microsatellite screening. Theor. Appl. Genet. 96:1110-1120.

Worland, A.J., E.J. Sayers, and A. Borner. 1994. The genetics and breeding potential of Rht12, a dominant dwarfing gene in wheat. Plant Breed. 113:187-196.

Worland, A.J., E.J. Sayers, and V. Korzun. 2001. Allelic variation at the dwarfing gene Rht8 locus and its significance in international breeding programmes. Euphytica 119:155-159.

Worland, T., and J.W. Snape. 2001. Genetic basis of worldwide wheat varietal improvement. p. 59-100. In A.P. Bonjean and W.J. Angus (ed.) The world wheat book: A history of wheat breeding. Lavoisier Publishing, Paris. 